\title{
Influence of life history traits on the population genetic structure of parasitic helminths: a minireview
}

\author{
Severo Vázquez-Prieto ${ }^{1,2}$, Román Vilas $^{3}$, Esperanza Paniagua ${ }^{1}$ and Florencio M. Ubeira ${ }^{1}$ \\ ${ }^{1}$ Laboratorio de Parasitología, Departamento de Microbiología y Parasitología, Facultad de Farmacia, Universidad de Santiago de \\ Compostela, Santiago de Compostela, Spain; \\ ${ }^{2}$ Universidad Autónoma de Chile, Temuco, Chile; \\ ${ }^{3}$ Departamento de Genética, Facultad de Biología, Universidad de Santiago de Compostela, Santiago de Compostela, Spain
}

\begin{abstract}
Parasite life history traits influence the rate of gene flow between populations and the effective population size, both of which determine the levels of genetic variability and the geographic distribution of such variability. In this short review targeted to parasitologists, we summarise how life history traits influence the population genetic structure of parasitic helminths. These organisms are characterised by a wide variety of life cycles and are ecologically different from microparasites, which have been studied in more detail. In order to provide the reader a concise review that illustrates key aspects of the subject matter, we have limited ourselves to studying examples selected for their clarity and relevance.
\end{abstract}

Keywords: reproduction modes, mating systems, long-lived infective stages, differences in longevity and generation time, parasitism intensity, host specificity, host mobility, life cycle complexity, transmission environment

Parasite life history traits, such as the mode of reproduction, host specificity and transmission mode, may have decisive effects on the rate of gene flow between populations and on the effective population size $\left(N_{\mathrm{e}}\right)$, thereby determining the genetic structure of parasite populations. Several reviews of this topic have already been published (Nadler 1995, Criscione et al. 2005, Huyse et al. 2005, Barrett et al. 2008, Gorton et al. 2012). Therefore, we will not attempt to provide a comprehensive overview here, but rather to make available to parasitologists a short review that highlights some key issues in parasitic helminths, a group of organisms that have varied and complex life cycles and that are ecologically different from microparasites.

For example, adult parasitic helminths release their progeny into the external environment and, in general, cannot multiply in their definitive host. Consequently, the intensity of a helminth infection can only increase as a result of new infection events (Hudson et al. 2002). Moreover, mating opportunities are restricted to the definitive hosts because breeders are subdivided into infrapopulations, i.e. all individuals of one parasite species present in a single host at a particular time (Bush et al. 1997). Microparasites may be more sensitive to the loss of genetic variability through the founder effect because microparasite infrapopulations often undergo recurrent generations and persist overtime (Vilas et al. 2011).
Here, we summarise how a set of life history traits affects the genetic structure of parasitic helminth populations. In order to provide the reader a concise review that illustrates key aspects of the subject matter, we have limited ourselves to studying examples selected for their clarity and relevance.

\section{EFFECTS OF LIFE HISTORY TRAITS ON POP- ULATION GENETIC STRUCTURE OF PARA- SITIC HELMINTHS}

\section{Mode of reproduction and mating system}

The parasite's mode of reproduction directly influences the distribution of genetic variability within and between populations. In general, species that undergo sexual recombination display higher genetic diversity than those that are exclusively asexual (Barrett et al. 2008). For example, trichostrongylid nematode populations that reproduce sexually are more diverse and less structured than other phylogenetically related nematodes that exhibit parthenogenesis, such as species of Strongyloides Grassi, 1879 and some entomopathogenic and plant parasitic nematodes (Anderson et al. 1998, Blouin 1998). However, in predominantly parthenogenetic populations of Strongyloides ratti Sandground, 1925, no significant genetic subdivision between different geographical sample sites was detected, presum-

Address for correspondence: S. Vázquez-Prieto, Laboratorio de Parasitología, Departamento de Microbiología y Parasitología, Facultad de Farmacia, Universidad de Santiago de Compostela, Campus Vida, Santiago de Compostela 15782, Spain. Phone: +34 881815004 ; Fax: +34 981 593316; E-mail: severovazquezprieto@gmail.com 
ably because of the mobility of its host, rat (Rattus rattus Linnaeus) and occasional sexual reproduction (Fisher and Viney 1998). This suggests that a relatively small fraction of sexual recombination and relatively low levels of gene flow may have an important influence on the population genetic structure.

The effect of asexual reproduction on the distribution of genetic variability within and between populations may vary from one stage of the life cycle to another, leading to different patterns of population genetic structure (Prugnolle and De Meeûs 2008). Thus, in parasites such as digeneans and some cestodes (e.g. species of Echinococcus Rudolphi, 1801) that reproduce asexually in intermediate hosts and sexually in definitive hosts, asexual reproduction will generate an excessive number of heterozygotes within the populations, relative to the number expected under panmixia. However, the populations will become more differentiated due to the presence of multiple genetically identical individuals in each. If natural selection is not shaping the clonal diversity, infrapopulations should show significant differences in the composition and size of clones due to chance, which would increase the genetic variance among populations (Prugnolle et al. 2005a,b).

Furthermore, the presence of different mating systems (selfing, biparental inbreeding or outcrossing) also influences the population genetic structure. For example, in the cestode E. granulosus (Batsch, 1786), which can reproduce by selfing or outcrossing, the predominance of selfing as a mating strategy may considerably erode the population genetic diversity and reduce $N_{\mathrm{e}}$. This reduction, insofar as it intensifies the effect of genetic drift, may cause geographical structuring in a context of limited gene flow (Lymbery et al. 1997).

However, outcrossing dominates the mating system of other hermaphroditic flatworms, which probably results in comparatively higher levels of genetic variability within populations and lower differentiation among populations (Šnábel et al. 1996, Vilas and Paniagua 2004, Criscione and Blouin 2006, Štefka et al. 2009). Further studies are needed to estimate selfing and outcrossing rates in hermaphroditic parasites and elucidate what, and how, factors influence their mating dynamics. Comparative analysis of trematodes may be of particular interest because the probability of selfing often depends on the intensity of infection. It is thus possible to assess how differences in the life cycle affecting this variable (e.g. differences in the availability of host species) of closely related species or even geographic populations of the same species determine the mating system and therefore the population genetic structure. For more discussion about mating systems in metazoan parasites, see Gorton et al. (2012).

\section{Long-lived infective stages, differences in longevity and generation time}

The presence of long-lived stages in the parasite life cycle is another important factor that may influence the population genetic structure because it favours the mix of different generations. The recruitment of different temporal samples represented by these stages by the same definitive hosts, which is where sexual reproduction takes place, may increase the genetic variation in the population and reduce the genetic differences between populations (Nadler 1995). For example, eggs of Ascaris lumbricoides Linnaeus, 1758 can remain viable for years and thus promote intergenerational mix and increase the genetic homogeneity among populations. This factor also contributes to increasing $N_{\mathrm{e}}$, partially offsetting the low intensity of parasitism that usually characterises populations of this species (for a more detailed discussion, see Criscione 2013). It has also been suggested that the poor survival of the nematode Dictyocaulus viviparus (Bloch, 1782) on pasture (Borgsteede et al. 1994), unlike many other parasitic nematodes that infect humans and livestock, may be a pertinent factor in explaining the high level of genetic differentiation detected between populations (Höglund et al. 2006). However, the mixing of temporal samples that differ substantially in allele frequencies, for example due to genetic drift, may lead to increased homozygosity through a transient Wahlund effect. This phenomenon is more likely in the presence of a combination of factors, such as a complex life cycle (e.g. involving paratenic hosts) and strong effects of genetic drift associated with high fecundity and mortality of the parasite. If a relatively small fraction of the population reaches the definitive host, different temporal samples could show significant differences in allele frequencies due to chance. The consideration of these samples as a single panmictic unit should cause the Wahlund effect. Thus, the potential deficit of heterozygotes results of an interaction between two opposing effects: the differentiation caused by drift and the homogeneity caused by temporal gene flow (Vilas et al. 2003, Criscione et al. 2011, Vázquez-Prieto et al. 2015).

The nematodes Haemonchus contortus (Rudolphi, 1803) and Teladorsagia circumcincta (Stadelmann, 1894) constitute another example of how differences in longevity and resistance to environmental conditions contribute to explaining different patterns of genetic structure in closely related taxa. Haemonchus contortus, which is a very prolific parasite with a short adult life expectancy, is characterised by a relatively low prevalence in temperate regions and a marked seasonal variation. Conversely, T. circumcincta is less prolific, has a longer adult life expectancy and is present throughout the year in temperate areas due to its eggs and free-living stages are able to survive for long periods on pasture (O'Connor et al. 2006). Silvestre et al (2009) found little genetic differentiation among populations of $T$. circumcincta, in contrast to the high degree of divergence detected in $H$. contortus. As the studied populations of $T$. circumcincta have been relatively isolated, the low degree of genetic structure was not attributed to the existence of gene flow between populations, but rather to a relatively large $N_{\mathrm{e}}$.

However, populations of $H$. contortus probably experience recurrent bottlenecks due to the existence of unfavourable periods that would decrease their $N_{\mathrm{e}}$, which would explain the higher degree of genetic differentiation between populations. Fluctuations in population size due to bottleneck events resulting from seasonal infection dy- 
namics have also been invoked as a possible cause, in combination with geographical isolation, for the strong structuring observed between subpopulations of Camallanus cotti Fujita, 1927, a parasite of fish with a two-host life cycle (Wu et al. 2009).

\section{Intensity of parasitism}

The intensity of parasitism depends on the host-parasite relationship and affects the evolution of the parasite to the extent that it affects $N_{\mathrm{e}}$. In general, it might be expected that a greater intensity of parasitism in the definitive host will yield a larger $N_{\mathrm{e}}$ because it is likely that larger infrapopulations contain the larger number and the greatest variation of breeders. However, several traits of the parasitic life style probably reduce $N_{\mathrm{e}}$ in comparison with that of free-living organisms for the same census size. For example, the significant demographic fluctuations caused by the contrast between high mortalities and high reproductive rates and the possibility of asexual reproduction may contribute to a smaller $N_{\mathrm{e}}$ (Criscione and Blouin 2005). In addition, a low intensity of parasitism may increase the rate of selfing in hermaphroditic parasites, or it may increase the chance of inbreeding if aggregated transmission of genetically identical individuals takes place (Criscione and Blouin 2006).

Furthermore, in many helminths like nematodes and cestodes, growth in the definitive host is intensity-dependent. At high intensity of infection, there are often a few large worms and many small worms. Since fecundity is proportional to body size in helminths, the few large worms can contribute disproportionally to the next generation, a factor that reduces $N_{e}$ (Poulin 2007). Intensity-dependent growth may also affect the longevity, in which case it might explain differences in population genetic structure. Again, comparative analysis would be useful to clarify this issue.

An example of how the intensity of parasitism influences the population genetic structure of helminth parasites is provided by $A$. lumbricoides and some trichostrongylid nematodes. Despite having direct life cycles and similar transmission modes, these nematodes differ in population genetic structure. Species characterised by large infrapopulations (in the order of thousands of individuals per host) such as nematodes of the genera Ostertagia Ransom, 1907, Teladorsagia Andreeva et Satubaldin, 1954 and Haemonchus Cobb, 1898 generally show higher levels of genetic variability and lower differentiation among populations than other nematodes such as $A$. lumbricoides whose populations include a few dozens of individuals per host (Anderson et al. 1993, 1995, Blouin et al. 1995, Nadler et al. 1995).

\section{Host specificity}

The degree of host specificity may influence the genetic structure of parasite populations by affecting the levels of parasite gene flow between host species (Nadler 1995, Criscione et al. 2005, Poulin and Keeney 2008). For example, parasites that mature sexually in a limited number of host species may display little gene flow between popula- tions, leading to strong genetic differentiation. However, if the hosts are particularly abundant, widespread and have high dispersal/mobility, the possibilities of gene flow for the parasites increase. In contrast, populations of parasites with a broad host range may show relatively high genetic variation and low differentiation because of a greater number of opportunities for gene flow (Archie and Ezenwa 2011, Falk and Perkins 2013). Ecological or behavioural differences between host species may also influence the population genetic structure. For example, the definitive host ecological differences that allow the host access to different prey species (intermediate hosts) could be involved in the contrasting patterns of population genetic structure of the trematode Neolebouria georgenascimentoi Bray, 2002 observed by López et al. (2015) in two fish species. Both definitive host species show a minimum overlap of prey and they have minimised trophic competition using different substrata.

Population dynamics and the evolution of parasite species exploiting a wide host range generally differ from those of parasites that infect only one species. Thus, generalist parasites are usually less well locally adapted to their hosts than specialist species (Lajeunesse and Forbes 2002). Furthermore, parasites with high gene flow between host species may be less likely to suffer extreme fluctuations in population numbers because they depend on the population dynamics of multiple host species, allowing them to maintain large $N_{\mathrm{e}}$ and high evolutionary potential (Dobson 2004, Barrett et al. 2008, Archie and Ezenwa 2011).

\section{Host mobility}

The spread of parasites depends on the mobility and dispersal ability of their hosts, which determines the extent of gene flow between parasite populations and contributes to shaping population genetic structure at local or regional scales (Criscione and Blouin 2004, Prugnolle et al. 2005c, Louhi et al. 2010, Belanger et al. 2011, Brouat et al. 2011, Blasco-Costa et al. 2012). The existence of mobile hosts or vectors in the life cycle usually leads to a high level of gene flow between parasite populations, thus reducing genetic differentiation between them. The gene flow can be enhanced by anthropogenic factors such as movement of domestic livestock (Blouin et al. 1995, Vilas et al. 2012) or use of faeces as fertiliser (Peng et al. 1998).

For example, Blouin et al (1995) compared the genetic structure of four species of trichostrongylid nematodes that infect domestic hosts [Ostertagia ostertagi (Stiles, 1892), T. circumcincta, Haemonchus placei (Place, 1893) and $H$. contortus] with that of a species that infects a wild host [Mazamastrongylus odocoilei (Dikmans, 1931)]. All populations studied showed a high degree of genetic diversity, but only helminth parasites infecting domestic hosts revealed a low degree of geographic structure. The authors attributed the difference to frequent transport of animals by farmers throughout the geographical area under study.

Relatively low levels of genetic differentiation were observed between populations species of Teladorsagia from St. Kilda (considered isolated for at least 70 years) and oth- 
er populations from UK (Braisher et al. 2004, Grillo et al. 2007). It has been suggested that the lack of differentiation may be determined by husbandry factors since the sheep population on St. Kilda is feral and so is not subject to anthelmintic selection pressures and potential population bottlenecks (Grillo et al. 2007). Leignel and Humbert (2001) detected significant genetic subdivision between populations of $T$. circumcincta that parasitise goats in central and southwest France probably due to breeding management practices (e.g. lack of contact between herds and anthelmintic treatment) and the length of isolation between the worm populations (more than 50 years). In addition, the different environmental conditions between these regions can also strongly influence the dynamics of the parasite populations and thus their evolution.

The presence of hosts that do not favour parasite dispersal contributes to enhancing the genetic structure and such populations often fit a model of isolation by distance. For example, populations of the nematode Heterorhabditis marelatus Liu et Berry, 1996, whose hosts are insects with limited mobility, show less genetic variation and higher subdivision than populations of parasites of mobile vertebrate hosts, such as trichostrongylids (Blouin et al. 1999). Obviously, host mobility also influences the genetic structure of parasites at infrapopulation level (Sire et al. 2001), especially if spatial aggregation of the infective stage occurs. For example, the aggregated distribution of metacercariae in the pasture, which favours the clumped transmission, in combination with the low mobility of the host, contributes to explaining the high degree of genetic differentiation between infrapopulations of Fasciola hepatica Linnaeus, 1758 in sheep (Vilas et al. 2012).

Theoretically, the dispersal ability of species that complete their whole life cycle in the aquatic environment (autogenic life cycle sensu Esch et al. 1988) is lower than that of species that mature in terrestrial hosts or fish-eating birds and only use fish as intermediate or paratenic hosts (allogenic life cycle). Therefore, autogenic species will display higher genetic subdivision in geographical space than allogenic species, because of the lower chance that gene flow will occur.

In accordance with this hypothesis, Criscione and Blouin (2004) studied populations of four species of digeneans that infect salmonids (species of Oncorhynchus Suckley) and observed a clearly higher degree of genetic structure in the three autogenic species [two species of Deropegus aspina (Ingles, 1936), called D. aspina A and D. aspina B, and Plagioporus shawi (McIntosh, 1939)] than in the fourth species [(Nanophyetus salmincola (Chapin, 1926)], whose life cycle includes highly mobile terrestrial hosts. A meta-analysis has recently been carried out to test the autogenic-allogenic hypothesis across all trematode species for which data are available (Blasco-Costa and Poulin 2013). The authors found that the type of life cycle was the best predictor of population genetic structure. This finding highlighted the dependence of parasites on host traits for their dispersal, suggesting that genetic differentiation of parasites reflects the mobility of their hosts.

\section{Life cycle complexity}

The presence of paratenic hosts in the life cycle may influence the genetic structure of parasite populations by determining the levels of gene flow in the parasites. For example, in the trematode Lecithochirium fusiforme Lühe, 1901, Vilas et al (2003) attributed the low level of genetic differentiation between adult infrapopulations to the accumulation of different parasite genotypes in small fish acting as paratenic hosts before being ingested by the definitive host (Conger conger Linnaeus). The existence of paratenic hosts may also explain the heterozygote deficiencies detected in the definitive host, due to the mixing of genetically distinct temporal samples of a population that are probably subjected to strong genetic drift (Vilas et al. 2003, Criscione et al. 2011).

Furthermore, the presence of intermediate hosts in the life cycle may increase the mixing of parasite genotypes in the definitive host, which reduces the probability of mating between genetically identical individuals (Rauch et al. 2005, Leung et al. 2009).

\section{Transmission environment}

Criscione and Blouin (2006) suggested that strictly aquatic parasite species with several intermediate hosts in their life cycle would integrate essentially panmictic populations (i.e. the 'aquatic mixing hypothesis'). These features may provide many opportunities for random mixing of parasite progeny before recruitment in the definitive host, where sexual reproduction takes place. Therefore, in aquatic habitats, a high degree of genetic mixing and low aggregate transmission of clones (if asexual reproduction occurs) to definitive hosts are predicted. This reduces potential mating between genetically identical individuals and, therefore, the possibility of inbreeding. Such populations will presumably show genotype frequencies consistent with the values expected under Hardy-Weinberg equilibrium.

In addition, in species with semi-aquatic transmission and terrestrial definitive hosts [e.g. Schistosoma mansoni Sambon, 1907, Fascioloides magna (Bassi, 1875) and $F$. hepatica], there is a high risk that eggs will be deposited in habitats that are unsuitable for transmission. This increases the variance in reproductive success between genotypes, which could explain the relatively low levels of genetic variability and relatively high population genetic structure (Mulvey et al. 1991, Théron et al. 2004, Prugnolle et al. 2005c, Vilas et al. 2012). However, purely aquatic species always deposit their eggs in water and the aquatic environment is conducive to larval dispersal, thereby enhancing the possibility of gene flow (Criscione and Blouin 2006). The aquatic mixing hypothesis has been confirmed empirically in both the definitive (Criscione and Blouin 2006, Criscione et al. 2011) and second intermediate hosts (Rauch et al. 2005, Keeney et al. 2007a,b, Leung et al. 2009, Valdivia et al. 2014). Cestodes with aquatic life cycles also appear to have panmictic populations (Renaud and Gabrion 1988, Šnábel et al. 1996). In contrast, high levels of inbreeding have been observed in terrestrial ces- 
todes (Lymbery et al. 1997, Knapp et al. 2008, Detwiler and Criscione 2011).

We have provided some examples that illustrate how certain life history traits of parasitic helminths influence the population genetic structure. However, current knowledge in this subject area is still limited. In this sense, it is important to conduct comparative studies of population genetic structure in helminth parasites that differ in key features of their life cycles by using similar sampling designs and genetic markers, as already done for example in Keeney et al. (2009) and Blasco-Costa et al. (2012).

In particular, it would be interesting to test if terrestrial life cycles promote a lower degree of mixing of parasite offspring, and thus more inbreeding, than semi- or fully aquatic life cycles. It would also be interesting to examine how the degree of host specificity and biological (e.g. behavioural, immunological or physiological) traits of the host species living in sympatry affect the population genetic structure. Another interesting question would be to explore the underlying factors that influence the mode of reproduction and mating systems in natural population of parasitic helminths. This type of information is essential for improving our understanding of how genetic diversity is organised in parasitic helminths and for predicting the evolutionary dynamics such as changes in drug resistance alleles, local adaptation and speciation.

Acknowledgements. This work was supported by grants GPC2014/058 from the Xunta de Galicia and AGL201130563-C03 from the Ministerio de Ciencia e Innovación, Spain. The authors wish to thank two anonymous reviewers for their helpful comments.

\section{REFERENCES}

Anderson T.J.C., Blouin M.S., Beech R.N. 1998: Population biology of parasitic nematodes: applications of genetic markers. Adv. Parasitol. 41: 219-283.

Anderson T.J.C., Romero-Abal M.E., Jaenike J. 1993: Genetic structure and epidemiology of Ascaris populations: patterns of host affiliation in Guatemala. Parasitology 107: 319-334.

Anderson T.J.C., Romero-Abal M.E., Jaenike J. 1995: Mitochondrial DNA and Ascaris microepidemiology: the composition of parasite populations from individual hosts, families and villages. Parasitology 110: 221-229.

Archie E.A., Ezenwa V.O. 2011: Population genetic structure and history of a generalist parasite infecting multiple sympatric host species. Int. J. Parasitol. 41: 89-98.

Barrett L.G., Thrall P.H., Burdon J.J., Linde C.C. 2008 Life history determines genetic structure and evolutionary potential of host-parasite interactions. Trends Ecol. Evol. 23: 678685.

Belanger D.H., Perkins S.L., Rockwell R.F. 2011: Inference of population structure and patterns of gene flow in canine heartworm (Dirofilaria immitis). J. Parasitol. 97: 602-609.

Blasco-Costa I., Poulin R. 2013: Host traits explain the genetic structure of parasites: a meta-analysis. Parasitology 18: 1-7.

Blasco-Costa I., Waters J.M., Poulin R. 2012: Swimming against the current: genetic structure, host mobility and the drift paradox in trematode parasites. Mol. Ecol. 21: 207-217.

BLOUin M.S. 1998: Mitochondrial DNA diversity in nematodes. J. Helminthol. 72: 285-289.

Blouin M.S., Liu J., BerRy R.E. 1999: Life cycle variation and the genetic structure of nematode populations. Heredity 83: 253-259.

Blouin M.S., Yowell C.A., Courtney C.H., Dame J.B. 1995: Host movement and the genetic structure of populations of parasitic nematodes. Genetics 141: 1007-1014.

Borgsteede F.H.M., Hendriks J., Leeuw W.A. 1994: Winter survival of Dictyocaulus viviparus in the Netherlands. Helminthologia 31: 9-15.

Braisher T.L., Gemmell N.J., Grenfell B.T., Amos W. 2004: Host isolation and patterns of genetic variability in three populations of Teladorsagia from sheep. Int. J. Parasitol. 34: 1197-1204.

Brouat C., Tatard C., Machin A., Kane M., Diouf M., Bâ K., Duplantier J.M. 2011: Comparative population genetics of a parasitic nematode and its host community: the trichostrongylid Neoheligmonella granjoni and Mastomys rodents in southeastern Senegal. Int. J. Parasitol. 41: 1301-1309.

Bush A.O., Lafferty K.D., Lotz J.M., Shostak A.W. 1997: Parasitology meets ecology on its own terms: Margolis et al. revisited. J. Parasitol. 83: 575-583.
Criscione C.D. 2013: Genetic epidemiology of Ascaris: cross-transmission between humans and pigs, focal transmission, and effective population size. In C. Holland (Ed.), Ascaris: The Neglected Parasite. Academic Press, London, UK, pp. 203 230.

Criscione C.D., Blouin M.S. 2004: Life cycles shape parasite evolution: comparative population genetics of salmon trematodes. Evolution 58: 198-202.

Criscione C.D., BLOUIN M.S. 2005: Effective sizes of macroparasite populations: a conceptual model. Trends Parasitol. 21: 212-217.

Criscione C.D., Blouin M.S. 2006: Minimal selfing, few clones, and no among-host genetic structure in a hermaphroditic parasite with asexual larval propagation. Evolution 60: 553-562.

Criscione C.D., Poulin R., Blouin M.S. 2005: Molecular ecology of parasites: elucidating ecological and microevolutionary processes. Mol. Ecol. 14: 2247-2257.

Criscione C.D., Vilas R., Paniagua E., Blouin M.S. 2011: More than meets the eye: detecting cryptic microgeographic population structure in a parasite with a complex life cycle. Mol. Ecol. 20: 2510-2524.

Detwiler J.T., Criscione C.D. 2011: Testing Mendelian inheritance from field-collected parasites: revealing duplicated loci enables correct inference of reproductive mode and mating system. Int. J. Parasitol. 41: 1185-1195.

Dobson A. 2004: Population dynamics of pathogens with multiple host species. Am. Nat. 164 (Suppl.): S64-S78.

Esch G.W., Kennedy C.R., Bush A.O., Aho J.M. 1988: Patterns in helminth communities in freshwater fish in Great Britain: alternatives strategies for colonization. Parasitology 96: 519-532.

Falk B.G., Perkins S.L. 2013: Host specificity shapes population structure of pinworm parasites in Caribbean reptiles. Mol. Ecol. 22: $4576-4590$

Fisher M.C., Viney M.E. 1998: The population genetic structure of the facultatively sexual parasitic nematode Strongyloides ratti in wild rats. Proc. R. Soc. B 265: 703-709.

Gorton M.J., Kasl E.L., Detwiler J.T., Criscione C.D. 2012: Testing local-scale panmixia provides insights into the cryptic ecology, evolution, and epidemiology of metazoan animal parasites. Parasitology 139: 981-997.

Grillo V., Jackson F., Cabaret J., Gilleard J.S. 2007: Population genetic analysis of the ovine parasitic nematode Teladorsagia circumcincta and evidence for a cryptic species. Int. J. Parasitol. 37: 435-447.

Höglund J., Morrison D.A., Mattsson J.G., Engström A. 2006: Population genetics of the bovine/cattle lungworm (Dic- 
tyocaulus viviparus) based on mtDNA and AFLP marker techniques. Parasitology 133: 89-99.

Hudson P.J., Rizzoli A., Grenfell B.T., Heesterbeek H., Dobson A.P. 2002: The Ecology of Wildlife Diseases. Oxford University Press, Oxford, UK, 218 pp.

Huyse T., Poulin R., Théron A. 2005: Speciation in parasites: a population genetics approach. Trends Parasitol. 21: 469-475.

Keeney D.B., King T.M., Rowe D.L., Poulin R. 2009: Contrasting mtDNA diversity and population structure in a direct-developing marine gastropod and its trematode parasites. Mol. Ecol. 18: 4591-4603.

Keeney D.B., Waters J.M., Poulin R. 2007a: Clonal diversity of the marine trematode Maritrema novaezealandensis within intermediate hosts: the molecular ecology of parasite life cycles. Mol. Ecol. 16: 431-439.

Keeney D.B., Waters J.M., Poulin R. 2007b: Diversity of trematode genetic clones within amphipods and the timing of sameclone infections. Int. J. Parasitol. 37: 351-357.

Knapp J., Guislain M.H., Bart J.M., Raoul F., Gottstein B., Giraudoux P., Piarroux R. 2008: Genetic diversity of Echinococcus multilocularis on a local scale. Infect. Genet. Evol. 8: 367-373.

Lajeunesse M.J., Forbes M.R. 2002: Host range and local parasite adaptation. Proc. Biol. Sci. B 269: 703-710.

Leignel V., Humbert J.F. 2001: Mitochondrial DNA variation in benzimidazole-resistant and susceptible populations of the small ruminant parasite Teladorsagia circumcincta. J. Hered. 92: 503-506.

Leung T.L.F., Poulin R., Keeney D.B. 2009: Accumulation of diverse parasite genotypes within the bivalve second intermediate host of the digenean Gymnophallus sp. Int. J. Parasitol. 39: 327-331.

López Z., Cárdenas L., Runil F., González M.T. 2015: Constrasting definitivehosts as determinants of the genetic structure in a parasite with complex life cyclealong the south-eastern Pacific. Mol. Ecol. 24: 1060-1073.

Louhi K.R., Karvonen A., Rellstab C., Jokela J. 2010: Is the population genetic structure of complex life cycle parasites determined by the geographic range of the most motile host? Infect. Genet. Evol. 10: 1271-1277.

Lymbery A.J., Constantine C.C., Thompson R.C.A. 1997: Self-fertilization without genomic or population structuring in a parasitic tapeworm. Evolution 51: 289-294.

Mulvey M., Aho J.M., Lydeard C., Leberg P.L., Smith M.H. 1991: Comparative population genetic structure of a parasite (Fascioloides magna) and its definitive host. Evolution 45: 16281640.

NADLER S.A. 1995: Microevolution and the genetic structure of parasite populations. J. Parasitol. 81: 395-403.

Nadler S.A., Lindquist R.L., Near T.J. 1995: Genetic structure of midwestern Ascaris suum populations: a comparison of isoenzyme and RAPD markers. J. Parasitol. 81: 385-394.

O'Connor L.J., Walkden-Brown S.W., Kahn L.P. 2006: Ecology of the free-living stages of major trichostrongylid parasites of sheep. Vet. Parasitol. 142: 1-15.

Peng W., Anderson T.J.C., Zhou X., Kennedy M.W. 1998: Genetic variation in sympatric Ascaris populations from humans and pigs in China. Parasitology 117: 355-361.

Poulin R. 2007: Evolutionary Ecology of Parasites. Second edition. Princeton University Press, Princeton, New Jersey, 332 pp.

Poulin R., Keeney D.B. 2008: Host specificity under molecular and experimental scrutiny. Trends Parasitol. 24: 24-28.

Prugnolle F., De Meeûs T. 2008: The impact of clonality on parasite population genetic structure. Parasite 15: 455-457.
Prugnolle F., Liu H., De Meeûs T., Balloux F. 2005a: Population genetics of complex life-cycle parasites: an illustration with trematodes. Int. J. Parasitol. 35: 255-263.

Prugnolle F., Roze D., Théron A., De Meeûs T. 2005b: F-statistics under alternation of sexual and asexual reproduction: a model and data from schistosomes (platyhelminth parasites). Mol. Ecol. 14: 1355-1365.

Prugnolle F., Théron A., Pointier J.P., Jabbour-Zahab R., Jarne P., Durand P., De Meeûs T. 2005c: Dispersal in a parasitic worm and its two hosts: consequence for local adaptation. Evolution 59: 296-303.

Rauch G., Kalbe M., Reusch T.B.H. 2005: How a complex life cycle can improve a parasite's sex life. J. Evol. Biol. 18: 10691075.

Renaud F., Gabrion C. 1988: Speciation of Cestoda: evidence for two sibling species in the complex Bothrimonus nylandicus (Schneider 1902) (Cestoda: Cyathocephalidae). Parasitology 97: 139-147.

Silvestre A., Sauve C., Cortet J., Cabaret J. 2009: Contrasting genetic structures of two parasitic nematodes, determined on the basis of neutral microsatellite markers and selected anthelmintic resistance markers. Mol. Ecol. 18: 5086-5100.

Sire C., Durand P., Pointier J.P., Théron A. 2001: Genetic diversity of Schistosoma mansoni within and among individual hosts (Rattus rattus): infrapopulation differentiation at microspatial scale. Int. J. Parasitol. 31: 1609-1616.

Šnábel V., Hanzelová V., Mattiucci S., D’Amelio S., PagGI L. 1996: Genetic polymorphism in Proteocephalus exiguus shown by enzyme electrophoresis. J. Helminthol. 70: 345-349.

ŠTEFKA J., HYPŠA V., SCHOLZ T. 2009: Interplay of host specificity and biogeography in the population structure of a cosmopolitan endoparasite: microsatellite study of Ligula intestinalis (Cestoda). Mol. Ecol. 18: 1187-1206.

Théron A., Sire C., Rognon A., Prugnolle F., Durand P. 2004: Molecular ecology of Schistosoma mansoni transmission inferred from the genetic composition of larval and adult infrapopulations within intermediate and definitive hosts. Parasitology 129: 571-585.

Valdivia I.M., Criscione C.D., Cárdenas L., Durán C.P., Oliva M.E. 2014: Does a facultative precocious life cycle predispose the marine trematode Proctoeces cf. lintoni to inbreeding and genetic differentiation among host species? Int. J. Parasitol. 44: 183-188.

Vázquez-Prieto S., Vilas R., Ubeira F.M., Paniagua, E. 2015: Temporal genetic variation of Fasciola hepatica from sheep in Galicia (NW Spain). Vet. Parasitol. 209: 268-272.

Vilas R., CaO A., Pardo B.G., Fernández S., Villalba A., MARTínez P. 2011: Very low microsatellite polymorphism and large heterozygote deficits suggest founder effects and cryptic structure in the parasite Perkinsus olseni. Infect. Genet. Evol. 11: 904-911.

Vilas R., Paniagua E. 2004: Estimation of the prevalence of outcrossing in the hermaphrodite trematode Lecithochirium rufoviride by allozyme analysis. Acta Parasitol. 49: 12-15.

Vilas R., Paniagua E., Sanmartín M.L. 2003: Genetic variation within and among infrapopulations of the marine digenetic trematode Lecithochirium fusiforme. Parasitology 126: 465-472.

Vilas R., Vázquez-Prieto S., Paniagua E. 2012: Contrasting patterns of population genetic structure of Fasciola hepatica from cattle and sheep: implications for the evolution of anthelmintic resistance. Infect. Genet. Evol. 12: 45-52.

Wu S.G., Wang G.T., Xi B.W., Xiong F., Liu T., Nie P. 2009: Population genetic structure of the parasitic nematode Camallanus cotti inferred from DNA sequences of ITS1 rDNA and the mitochondrial COI gene. Vet. Parasitol. 164: 248-256. 